\title{
Histórico das avaliações institucionais e sua mudança na percepção de valor
}

History of institutional assessments and their change in value perception

\author{
Francisca Goedert Heiderscheidt ${ }^{1}$ \\ Fernando Antônio Forcellini ${ }^{2}$
}

Resumo: A avaliação, sobretudo da qualidade da educação, é essencial para que a sociedade saiba o que está sendo produzido nas universidades. Portanto, a busca pela qualidade na educação tem sido objeto de estudo de diversas áreas de conhecimento, e, pode-se dizer que a área de avaliação institucional tem ganhado força nos últimos tempos, tendo em vista os desafios impostos que envolvem, acima de tudo, o diagnóstico de quão bem estão as instituições de ensino. Por meio da avaliação institucional é mapeada a realidade da instituição, que é o alicerce para proposições de ações de melhoria. Assim, esse artigo tem como objetivo identificar o que as instituições de ensino superior consideram valor no processo de avaliação. Essa pesquisa exploratória analisa o valor nos estudos sobre avaliação institucional e aponta a inovação como caminho determinante. A inovação nesse processo se torna crucial e a gestão da transição é uma lente que auxilia na identificação dos atores envolvidos, bem como na concretização da implementação dessa transição sociotécnica, com foco na mudança social e cultural.

Palavras-chave: Educação superior. Avaliação institucional. Inovação. 
Abstract: The assessment, especially the quality of education, is essential for society to know what is being produced in universities. Therefore, the search for quality in education has been the subject of study in several areas of knowledge, and it can be said that the area of institutional assessment has gained strength in recent years, given the challenges imposed by the diagnosis of how well the educational institutions are. Through institutional assessment, the reality of the institution is mapped, which is the substance for propositions of improvement actions. Thus, this article aims to identify what higher education institutions consider value in the evaluation process. This exploratory research analyzes the value in institutional assessment studies and points out innovation as the determining path. Innovation in this process becomes crucial and transition management is a lens that assists in the identification of the actors involved, as well as in the implementation of this socio-technical transition, focusing on social and cultural change.

Keywords: Higher education. Institutional assessment. Innovation.

${ }^{1}$ Universidade Federal de Santa Catarina | Programa de Pós-graduação em Engenharia de Produção | Florianópolis | SC | Brasil. Contato: fghfrancisca@gmail.com. ORCID: https://orcid.org/0000-0003-4954-3455

${ }^{2}$ Universidade Federal de Santa Catarina | Programa de Pós-graduação em Engenharia de Produção | Florianópolis | SC | Brasil. Contato: forcellini@gmail.com. ORCID: https://orcid.org/0000-0003-2851-6028

- Recebido em: 9 de janeiro de 2020

- Aprovado em: 10 de junho de 2020

DOI: http://dx.doi.org/10.1590/S1414-40772021000100010

Este é um artigo publicado em acesso aberto sob uma licença Creative Commons

https://creativecommons.org/licenses/by-nc/4.0/ 


\section{Introdução}

O cenário atual em que vivemos reflete um mundo globalizado, competitivo e cheio de inovações organizacionais e tecnológicas. E esse panorama de rápidas transformações vem exigindo das instituições respostas ágeis no sentido de atendimento à diversidade de demanda em que se deparam e, muitas vezes, da capacidade de resposta a grandes desafios. Essa realidade não difere nas instituições ensino superior (IES). Com uma crescente demanda e grande depressão orçamentária, é exigido das IES respostas a desafios cada vez mais complexos.

A avaliação é uma atividade corriqueira na vida humana. Sua onipresença manifesta-se nas relações interpessoais e profissionais e permite revisões constantes de comportamentos, atuações e condutas. De maneira restrita, seu sentido foi historicamente construído nos espaços escolares como instrumento de medição, direcionado para resultados. A avaliação é uma realidade nas instituições de ensino superior do país. Faz-se presente em todas as atividades de ensino, pesquisa e extensão, e mesmo nas práticas administrativas de uma universidade.

Entretanto, reconhece-se que a maioria das instituições de ensino superior desenvolve a avaliação por pressão direta e/ou indireta de órgãos de controle ou simplesmente para cumprir a legislação. Muitas avaliações se tornam inócuas no sentido de atender o que deveria ser seu objetivo primário. Ainda, muitos dos avaliadores dos cursos de graduação têm observado que os instrumentos do Sistema Nacional de Avaliação da Educação Superior (SINAES) são cumpridos como uma função burocrática, não sendo construídos coletivamente com a efetiva participação da comunidade acadêmica (CORRÊA et al., 2013). Em uma perspectiva histórica e inserida em um contexto dinâmico, o objetivo do presente estudo é identificar o que as IES consideram valor no processo de avaliação.

Este artigo está estruturado em cinco seções: (1) Esta introdução, que contextualiza o leitor, apresenta a natureza do problema da pesquisa, aponta o objetivo e descreve a estrutura do artigo; (2) Fundamentação Teórica, com um panorama sobre avaliação institucional em instituições de ensino superior e uma breve retrospectiva histórica, conceitos de avaliação de desempenho e valor inseridos nesse contexto; (3) Procedimentos Metodológicos para a realização desta pesquisa; (4) Apresentação e Discussão dos Resultados, contendo a percepção de valor nas avaliações institucionais das IES e a necessidade de inovação nesse processo por meio da gestão da transição sociotécnica e por fim, (5) Considerações Finais. 


\section{Fundamentação teórica}

A fim de situar e prover embasamento teórico ao leitor, essa seção abrange conteúdo sobre avaliação institucional em instituições de ensino superior, apresentando uma breve retrospectiva histórica sobre esse processo. Também, traz conceitos sobre avaliação de desempenho, assim como valor e desperdício aplicados a esse cenário.

\subsection{Avaliação institucional em instituições de ensino superior}

A avaliação do ensino superior é considerada um importante instrumento para buscar a qualidade e melhoria do ensino. Ela tem sido desenvolvida desde os anos 1970 e atualmente tem sido destaque e prioridade das instituições brasileiras. É um processo fértil para a geração e adoção de práticas inovadoras. Entretanto, não há indícios empíricos de que isso é o que realmente ocorra, pelo menos no cenário da educação superior brasileira (BALDIGEN, 2018). Apesar das diversas dificuldades e barreiras apontadas, a avaliação da qualidade das instituições de ensino superior tem se tornado um tema de pesquisa recorrente em todo o mundo (STEINHARDT et al., 2016).

Segundo Pederneiras et al. (2011), a avaliação institucional surge como um movimento importante, uma alternativa para a autorreflexão. Essa importância se dá em âmbito nacional, sendo dirigida por discussões, propostas e projetos, agregando valores, demonstrando caráter formativo e sendo vista como instrumento de gestão. A avaliação é um ganho para a universidade, possibilitando o pensar de modo sistemático sobre a natureza da instituição e o seu papel na atualidade, conduzindo à busca da coerência entre o que se diz e o que se faz, proporcionando a reflexão sobre a manutenção ou modificação de prioridades.

Assim, a cultura de avaliação pode ser entendida como um conjunto de valores acadêmicos, atitudes e formas coletivas resultantes das funções existentes na universidade. Essa afirmação é útil para se compreender a cultura de avaliação como relacionada às práticas da comunidade acadêmica, em especial à prática avaliativa (RISTOFF, 1999). A sensibilização pode ser vista como algo mais que a transmissão de informações; é criar condições diretas ou indiretas para que os atores envolvidos se insiram no processo de construção e compreensão das informações, bem como sua utilização no cotidiano institucional. Desejando alcançar esse objetivo, a sensibilização do público de interesse deve ser realizada em todas as etapas do processo da avaliação.

Em uma instituição de ensino deve existir um envolvimento com a alta qualificação das atividades de pesquisa, cooperação, ensino e prestação de serviços para que o compromisso seja 
assegurado. Dessa forma, o compromisso com a realidade de cada instituição se expressa na participação ativa no processo de desenvolvimento social, cultural e econômico, traduzido em ações institucionais definidas a partir das demandas e necessidades detectadas pela comunidade acadêmica. A comunidade acadêmica constituída pelos docentes, discentes e funcionários técnico-administrativos deve ter um compromisso institucional. Esse envolvimento deve ser tanto nas discussões sobre a concepção, as finalidades e o desenho da avaliação quanto também, do levantamento, da organização das informações e dos dados, das pesquisas e das interpretações que dão continuidade ao processo avaliativo.

\subsubsection{Breve retrospectiva histórica da avaliação institucional em IES}

A ideia de avaliar as universidades não é nova. Ela sempre, formal ou informalmente, ocorreu. Segundo Neiva (1987), ela sempre apareceu no dia a dia da universidade, mesmo que de forma difusa, em relatórios a órgãos superiores, confecção de estatísticas e outras informações de competência e responsabilidade de órgãos da estrutura interna da universidade.

O sistema de avaliação do ensino superior no Brasil iniciou no final dos anos 1970, porém nos anos 1980, a experiência da Comissão de Aperfeiçoamento do Pessoal Superior (CAPES) na avaliação da pós-graduação do país levou o então diretor-geral da CAPES a propor o Programa de Avaliação da Reforma Universitária (PARU) (CUNHA, 1997). Assim, em 1983, surgiu a primeira proposta de avaliação do ensino superior no Brasil. O PARU tinha o intuito discutir por meio de questionários aplicados a estudantes, dirigentes e docentes de universidades, os temas gestão, produção e disseminação de conhecimentos. Era considerada necessária a participação, especialmente, da comunidade acadêmica, realizando um processo de reflexão sobre sua própria prática e de outros setores externos às instituições, sobretudo, na expressão de demandas e expectativas quanto ao papel da universidade e sua organização. $\mathrm{O}$ PARU, talvez pela sua ligação com a CAPES, que congrega a pós-graduação e grande parte da pesquisa do país e pelo perfil dos integrantes do seu grupo gestor, adquiriu a forma de um projeto de pesquisa sobre o estado da educação superior no país. Isso imprimiu a ele caráter de busca, indagação, investigação que fundamentaria ações futuras, o que o diferencia de documentos afirmativos e propositivos posteriores (BARREYRO; ROTHEN, 2008).

A Comissão Nacional Para Reformulação da Educação Superior foi instituída visando à reformulação da educação superior, no marco da redemocratização do país, com a instauração da Nova República. Em linhas gerais, defendeu-se a superação da crise da universidade 
brasileira aumentando a autonomia universitária que seria acompanhada por um processo externo de avaliação baseado na valorização de mérito acadêmico.

Em 1986 a criação do Grupo Executivo para Reformulação da Educação Superior (GERES) e da Proposta de Avaliação do Ensino Superior, que foi um projeto instituído pela Universidade de Brasília (UnB), ambos foram de suma importância, pois criaram estratégias que colaboraram com o processo de avaliação institucional. Houve o aumento (BARREYRO; ROTHEN, 2008) da autonomia universitária e a avaliação da responsabilidade social mediante processos públicos com critérios estabelecidos pela própria comunidade acadêmica. A ideia do binômio autonomia/avaliação referendada pela comunidade acadêmica seria um dos pontos nevrálgicos da argumentação. O controle das instituições não seria mais burocrático e ritualista e passaria a ser realizado pelos processos de avaliação institucional, deixando de verificar o cumprimento da legislação e averiguando o desempenho institucional.

Em 1993, no âmbito do Ministério da Educação foi criado um programa de apoio à avaliação do sistema de ensino superior, denominado Programa Nacional de Avaliação Institucional das Universidades Brasileiras (PAIUB). Esse programa tinha como intuito a adesão voluntária das universidades brasileiras, sendo primordial a autoavaliação da instituição, que consequentemente, daria as informações necessárias para a realização de uma avaliação externa, ou até mesmo de uma reavaliação, pois a programa previa continuidade e sistematização do processo. Outro fator de grande relevância no PAIUB foi que por meio do caráter institucional e global desta proposta as universidades puderam desencadear seus processos de avaliação institucional (BESE, 2007).

A grande contribuição dessa primeira iniciativa, em termos de avaliação institucional, foi a ênfase na necessidade de se elevar a qualidade das atividades acadêmicas (ensino, pesquisa e extensão), e também de se criar processos e procedimentos avaliativos conduzidos pelas próprias instituições de ensino superior. No entanto, em virtude de seu caráter voluntário e nãopunitivo, essa política de avaliação teve baixo índice de adesão, atingindo mais especificamente, o universo das universidades federais e públicas brasileiras.

Em 1995, o Exame Nacional de Cursos (ENC) foi instituído e seu principal objetivo era medir as aprendizagens dos graduandos de último ano, para então avaliar externamente o curso, reordenando assim o modelo brasileiro de avaliação institucional. Essa estratégia de avaliação foi reconhecida pela sociedade, como processo de classificação das universidades; que na verdade avaliava de forma fragmentada, desconsiderando os fatores determinantes do desempenho dos estudantes e principalmente o contexto local e institucional dos cursos (BESE, 2007). 
Nos anos de 2003, o Ministro da Educação regulamentou a Comissão Especial de Avaliação (CEA), que tinha como objetivo oferecer subsídios, fazer recomendações, propor critérios e estratégias para reformulação dos processos e políticas da educação superior e elaborar a revisão crítica dos seus instrumentos, metodologias e critérios utilizados. A Comissão Especial de Avaliação sugeriu ao Ministério da Educação, a criação da Comissão Nacional de Avaliação da Educação Superior (CONAES), para que a mesma passasse a coordenar e supervisionar o Sistema Nacional de Avaliação da Educação Superior, assegurando assim, o funcionamento e cumprimentos dos princípios e orientações gerais estabelecidos e vinculados à política pública de educação superior.

Hoje, a avaliação institucional continua sendo guiada pelo SINAES que propõe diretrizes voltadas à pluralidade de aspectos relativos ao universo acadêmico, possibilitando às instituições construírem instrumentos de avaliação que detectem as fragilidades e as potencialidades institucionais para a melhoria da qualidade da oferta educacional em todos os sentidos (BRASIL, 2004). A ênfase do SINAES recai sobre a implantação de um processo de autoavaliação sério e transparente como fórmula mais adequada de prestação de contas à sociedade. Embora o SINAES possa ser considerado uma tentativa bem sucedida de reunir num só momento todas as faces da avaliação universitária, adotando uma visão sistêmica e integrando todos os dados obtidos em diferentes práticas avaliativas, no decorrer do tempo, a concepção inicial do SINAES centrada na instituição como um todo se deslocou para um processo marcadamente regulatório (RIBEIRO, 2015; FRANCISCO et al., 2015). Isso pode ser evidenciado pela criação de critérios mínimos para atestar a qualidade das instituições educacionais e de conceitos obtidos em função do atendimento ou não dos critérios estabelecidos.

\subsection{Avaliação de desempenho}

Embora o argumento da qualidade seja o motriz da avaliação, percebe-se que há interesse no nivelamento das instituições a partir de determinados indicadores de desempenho, de modo que se eleve o padrão e, por fim, melhore a qualidade das IES, o que pode ser constatado ao longo da trajetória de dezesseis anos do SINAES: o caráter regulatório e de supervisão, sobrepondo sua concepção inicial.

Para Dias Sobrinho (2001) e Ristoff (1999), os resultados das análises das relações entre os diversos indicadores externos e internos da avaliação institucional necessitam ser submetidos a uma avaliação qualitativa geral, de forma prévia a um processo em novos patamares. A 
integração entre as dimensões avaliadas, considerando os diversos agentes e processos previamente relatados, além de contemplar os eixos do SINAES proporciona percepção global da vida institucional e torna notória a complexidade e riqueza do inter-relacionamento da avaliação institucional, além de permitir um diagnóstico de uma IES e suas análises comparativas frente a outras instituições nacionais e internacionais.

A mensuração do desempenho tem evoluído de medidas financeiras e não financeiras predominantes na década de 1990, para estruturas mais complexas, baseadas no conjunto equilibrado de medidas que buscam alinhar essas medidas à estratégia da organização. Esse processo surge como questão fundamental na gestão das organizações. Sem esses sistemas de medição, as organizações dificilmente lidariam de forma eficiente e eficaz com a incerteza inerente ao ambiente, resultando em utilização deficiente dos recursos e, consequentemente, no aumento da probabilidade de insucesso (VIEIRA; MAJOR; ROBALO, 2009).

Sendo assim, os indicadores devem ser encarados como o que na realidade são: artefatos de alcance limitado, ou seja, de eficácia relativa (VAN RAAN, 2005). Por que, então, sua relevância e acentuada difusão são verificadas atualmente no campo educacional? Sem dúvida alguma, o motivo principal se encontra em duas características intrínsecas aos indicadores: (1) caráter sintético e (2) capacidade para orientar a tomada de decisões. A seleção de um conjunto limitado, mas significativo, de indicadores, permite que se possa ter uma ideia sumária do funcionamento de uma dada realidade, contribuindo, assim, para compreendê-la de forma mais acurada. Por outra parte, essas características de síntese têm revelado seu valor, especialmente para as pessoas que necessitam contar com informações úteis e confiáveis para a tomada de decisões, como é o caso dos gestores de IES.

A indução à busca de soluções factíveis para os problemas ou dificuldades detectadas pelos indicadores, com vistas ao aprimoramento da instituição, realça a função vital da avaliação institucional: servir ao planejamento estratégico da organização. Para tal, a referida atividade deverá ser sistemática e rotineira. A explicação e a interpretação da realidade educacional são tarefas complexas, que exigem diversos enfoques teóricos, uso de procedimentos técnicos variados e necessidade de participação e contribuição de distintos protagonistas ou atores da realidade avaliada (ANDRIOLA; ARAÚJO, 2018), no entanto, essa expansão dos sistemas de medição de desempenho organizacional fez surgir uma visão menos restritiva e mais holística do desempenho. Uma das mais relevantes funções da mensuração do desempenho é proporcionar informação à tomada de decisão e, por consequência, contribuir para a criação de valor. 


\subsection{Valor}

Acadêmicos e profissionais estão muito interessados em como as organizações são mensuradas e como extraem valor dos dados que coletam. A análise do valor teve origem durante a $2^{\text {a }}$ Guerra Mundial, como resultado da aplicação de conceitos desenvolvidos por Lawrence Delos Miles, que chegou a algumas conclusões explicitando que o uso dos padrões convencionais sufoca a imaginação e restringe o campo de observações relativo aos objetos existentes (MILES, 2019), ou seja, desde a primeira metade do século XX já se falava em algo como "inovação". Atualmente, a obrigação das organizações se torna múltipla devido à mudança dinâmica nos negócios, às tendências globais e naturais (BITITCI et al., 2012) e aos requisitos tecnológicos. Como estratégia para a obtenção de diagnóstico situacional da IES a partir das respectivas interpretações dos valores obtidos e das tendências identificadas, permitese a emissão de valorações acerca desses aspectos institucionais, caracterizando a execução de uma autêntica avaliação (ANDRIOLA; ARAÚJO, 2018).

Os stakeholders são indivíduos ou organizações que estão envolvidos direta ou indiretamente no processo. A identificação dos interessados é crucial, uma vez que eles são quem demanda o valor. Além de determiná-los, deve-se identificar suas expectativas. Importante ressaltar que o valor é uma percepção subjetiva, assim como os benefícios extraídos dele e os esforços para alcançá-lo.

O valor pode ser considerado como uma função não só do produto ou serviço, mas como a experiência total obtida em relação a esse produto ou serviço. Também, o valor para cada interessado está relacionado em como eles percebem o retorno financeiro, utilidade, benefício, rapidez ou recompensa em troca de sua respectiva contribuição para a empresa que entrega o produto ou serviço. $\mathrm{O}$ valor não é universal para todos os interessados e, mesmo no contexto de um interessado específico, a percepção de valor evolui com o tempo, com as circunstâncias e com as prioridades. O benefício advém da utilização dos resultados do processo, por parte dos stakeholders, podendo ser tangível ou intangível, assim como o esforço.

Assim, atividade agregadora de valor em uma universidade é aquela que consegue aumentar o desempenho técnico do serviço prestado, bem como o prestígio por fazer parte daquela comunidade acadêmica, ao passo que reduz os esforços para tal. Assim, o valor está atrelado a uma imagem mental feita por comparação no momento da escolha por aquela instituição. Assim, faz-se necessário eliminar o desperdício com o objetivo de criar valor (MURMAN et al., 2002), ou seja, eliminar as atividades que não agregam valor, reduzir as que não agregam, mas são necessárias e manter ou aumentar as atividades que já possuem valor 
agregado do ponto de vista do envolvido no processo. Apenas quem sabe o que é valor pode falar em remover desperdícios.

Os valores podem ser econômicos, pois quanto maior o conceito obtido por uma universidade em uma avaliação de desempenho, maiores também são os recursos financeiros que o Governo destina a ela, mas pelas peculiaridades do objeto de estudo (universidades), esse artigo se direciona para aumentar o valor do ponto de vista social.

\section{Procedimentos metodológicos}

Essa pesquisa, sob o ponto de vista da sua natureza, é caracterizada como pesquisa aplicada, pois objetiva gerar conhecimentos para aplicação prática, dirigidos à solução de problemas específicos, envolvendo interesses locais (PRODANOV, 2013).

Sob o ponto de vista de seus objetivos, incialmente é caracterizada como pesquisa exploratória porque tem como finalidade proporcionar mais informações sobre o assunto a ser investigado, possibilitando sua definição e seu delineamento. Em fase posterior, é descrita como pesquisa explicativa, pois se procura explicar os porquês das coisas e suas causas, por meio do registro, da análise, da classificação e da interpretação dos fenômenos observados. Visa identificar os fatores que determinam ou contribuem para a ocorrência dos fenômenos, aprofundando o conhecimento da realidade (GIL, 2010).

Importante notar que essa pesquisa, de acordo com as diversas classificações, pode ser usada de forma concomitante, isto é, uma mesma pesquisa pode adotar característica de mais de um tipo (PRODANOV, 2013). Assim, quanto aos procedimentos técnicos - a maneira pela qual se obtém os dados necessários para a elaboração da pesquisa - esse artigo é caracterizado em (1) pesquisa bibliográfica porque foi elaborada a partir de material já publicado, constituído principalmente de publicações em livros, periódicos e artigos científicos, dissertações e teses com o objetivo de colocar o pesquisador em contato direto com todo material já escrito sobre o assunto da pesquisa e; (2) Pesquisa documental, pois segundo Gil (2010) baseou-se também em documentos que, de alguma forma, já foram analisados, tais como relatórios institucionais. Martins (2006) ressalta que como estratégia de pesquisa que orientará a busca de explicações e interpretações convincentes para situações que envolvam fenômenos sociais complexos.

Para alinhar a busca aos interesses desse artigo, fez-se uso de dois eixos: "Avaliação" e "Instituição de Ensino Superior" em três bases de dados relevantes para o tema: Scopus, Web of Science e Scielo. Não houve restrição temporal e inicialmente se analisou documentos nas línguas inglesa e portuguesa. A pesquisa foi caracterizada como qualitativa composta por 
práticas interpretativistas, tentando dar sentido as coisas em seus ambientes naturais ou interpretar fenômenos (CRESWELL, 2006).

\section{Apresentação e discussão dos resultados}

Baseado no referencial bibliográfico desenvolvido neste artigo, esta seção visa identificar a percepção de valor nas avaliações institucionais das IES e apontar os envolvidos capazes de propor melhorias nesse processo.

\subsection{Percepção de valor nas avaliações institucionais das IES}

Segundo Bititci et al. (2012), um dos desafios da avaliação de desempenho é entender o envolvimento dessa com a cultura e em qual direção as práticas precisam ser mudadas para serem efetivas. Esse estudo afirma a necessidade de mudança de propósito que envolva as pessoas, as redes de trabalho (internas e externas) e a avaliação de desempenho como um sistema de aprendizado dinâmico. Também corrobora a ideia dos autores no sentido de que tão importante quanto aprimorar os processos e a tecnologia, é melhorar as pessoas inseridas naquele sistema. Isso envolve uma mudança de mentalidade, de cultura, de valores. Assim, essa seção enseja identificar o valor no processo de avaliação institucional dos estudos identificados conforme o procedimento metodológico proposto (Quadro 1).

Quadro 1 - Percepção de valor nas avaliações institucionais das IES

\begin{tabular}{|c|c|}
\hline Valor da avaliação & Estudo \\
\hline Autonomia & Felix, Bertolin e Polidori (2017) \\
\hline Monitoramento & Bauren e Teixeira (2014) \\
\hline Mensuração da qualidade & Hoffmann et al. (2014) \\
\hline Integração de avaliação interna e externa & Castro et al. (2018) \\
\hline Inovação & Baldigen (2018) \\
\hline
\end{tabular}

Fonte: Elaborado pelos autores (2020).

Embora não haja restrição temporal na busca pelos artigos, é notória a atualidade dos estudos nessa área. Felix, Bertolin e Polidori (2017) relatam o valor da avaliação institucional na autonomia universitária, Bauren e Teixeira (2014) apontam esse processo na forma de monitoramento da instituição e Hoffmann et al. (2014) percebem o valor da avaliação institucional como forma de mensurar a qualidade. A integração das avaliações interna e externa é proposta por Castro et al. (2018).

Felix, Bertolin e Polidori (2017) realizam uma análise comparativa dos instrumentos de regulação do Brasil e Portugal, sempre focando na obtenção da autonomia para a instituição. 
Vários autores criticam a avaliação institucional como função regulatória (FRANCISCO et al., 2015; FELIX; BERTOLIN; POLIDORI, 2017; RIBEIRO, 2015), enquanto outros sugerem inconsistência no histórico de avaliação (FALLEIROS; PIMENTA; VALADÃO, 2016).

Apesar dos avanços em relação às práticas de avaliação institucional no Brasil, o SINAES parece não ter conseguido institucionalizar plenamente a avaliação, sobretudo porque está organizado para dar conta, simultaneamente, de duas finalidades distintas: o aperfeiçoamento e desenvolvimento institucional de um lado, e a regulação do outro.

Percebe-se que, nesses estudos, a percepção de valor (ou do que não é valor) nas avaliações institucionais converge para a necessidade de uma mudança. Essa mudança perpassa os processos e a tecnologia, necessitando atingir as pessoas. A inovação permite mudanças ao passo que aumenta os benefícios e reduz os esforços.

\subsection{Inovação nas avaliações institucionais das IES}

Há necessidade de inovação nos processos de avaliação institucional, visando garantir a qualidade das instituições de ensino superior frente a um cenário de escassos recursos e significativas mudanças tecnológicas e sociais. Os novos instrumentos de avaliação também indicam uma clara valorização dos processos de inovação. No instrumento de recredenciamento o uso da palavra "inovação" apareceu 29 vezes (SEMESP, 2018).

Pucciarelli e Kaplan (2016) citam que as universidades são recursos essenciais para as sociedades, pois oferecem um serviço institucionalizado que provê conhecimento e inovação, além de serem direcionadores em nível regional, nacional e global, gerando a disseminação de conhecimento. Ainda, os autores citam a rápida expansão das tecnologias de informação e comunicação no ambiente do ensino superior, desenvolvendo novos mercados, gerando ganhos de produtividade e possibilidades, e uma rápida transformação sociodemográfica, com os millennials buscando experiências educacionais e crescimento. Todas essas oportunidades estão presentes, em menor ou maior grau, no cenário da educação superior no Brasil.

Para Venturini et al. (2010), a avaliação pode ser uma estratégia institucional para construir uma ligação efetiva com a realidade social e, por isso, implementar um processo de avaliação numa universidade acarretará transformações intensas, que poderão atingir todos os indivíduos que dela fazem parte, assim como todos os processos nela existentes. A avaliação institucional, portanto, deve impulsionar transformações organizacionais, assim como as mudanças produzem alterações nos processos avaliativos. 
A educação tem um caráter público e um papel importante na construção e desenvolvimento de uma sociedade e a pergunta de como a inovação pode contribuir para a inovação social é de interesse tanto de pesquisadores quanto de praticantes e tomadores de decisão. Entende-se aqui que as tecnologias para a inovação social requerem uma reordenação de estruturas sociais e mudanças sociais.

\subsubsection{Transição sociotécnica}

As transições sociotécnicas são transformações no modo como as funções sociais são cumpridas, incluindo uma mudança social. Por meio de uma configuração sociotécnica em associação com a atividade humana é que a tecnologia cumpre funções, sendo essa um alinhamento entre um conjunto heterogêneo de elementos (GEELS, 2002). Ressalta-se que a transição se caracteriza como o deslocamento de um equilíbrio dinâmico inicial para um novo paradigma, envolvendo inovações em dimensões técnicas e socioculturais (KEMP; ROTMANS, 2010). Nesse sentido, a transição sociotécnica implicou não somente o uso de novas tecnologias, mas na alteração de mercados, práticas, políticas e culturas. Essa transição pode ser entendida como uma nova visão para a solução de problemas e preocupações da sociedade, numa perspectiva multinível e complexa (GEELS, 2011). As reconfigurações sociotécnicas levam ao entendimento de que o todo é resultado do trabalho das partes gerando um novo contexto.

A gestão da transição sociotécnica permite auxílio na identificação dos envolvidos a fim de identificar valor da respectiva perspectiva. As metas para transição são de longo prazo e informam a direção da mudança de maneira coordenada. Para uma transição efetiva, os atores políticos, bem como o apoio regulatório e institucional são fatores fundamentais. Essa estrutura pode ser usada para analisar, estruturar ou gerenciar os processos de governança em andamento na sociedade. Cada vez mais, também é visto internacionalmente como uma interessante abordagem para mobilizar, orientar e acelerar a inovação social rapidamente. Elas foram projetadas para criar espaço para inovação de curto prazo e desenvolver visões de sustentabilidade de longo prazo ligadas às transições sociais desejadas.

O surgimento da gestão da transição pode, nessa luz, ser visto como uma ruptura com a tradição consensual de formulação de políticas com abordagens dominantes. Vários processos de governança baseados na gestão de transição foram desenvolvidos em diversos setores e regiões nos últimos anos (LOORBACH, 2007). Trata-se de reunir múltiplos pontos de vista a 
respeito de determinada necessidade, contando com profissionais que já enfrentaram inúmeras vezes os desafios de uma determinada transição.

Assim, seu objetivo está em criar um movimento social, por meio de coalizões, parcerias e redes, em arenas que permitam uma pressão contínua na esfera política e de mercado, não somente voltado para uma transição, mas também para a melhoria de sistemas existentes. Nessa perspectiva multinível, Geels (2002) define uma hierarquia em que o ambiente sociotécnico externo (nível macro) é transformado pelo regime existente (nível meso) que por sua vez, molda a inovação que surge em nível de nicho (nível micro) (Figura 1).

Figura 1 - Atores da avaliação institucional sob a lente da Gestão da Transição



Fonte: Elaborada pelos autores (2020).

O nível do ambiente socioténico é definido como os desenvolvimentos exógenos, mais amplos e contextuais em padrões culturais arraigados, macroeconomia, macropolítica e estruturas espaciais, potencialmente decorrentes de choques associados a crises econômicas, desastres naturais e convulsões política. Também, é composto pelos valores sociais, crenças, preocupações, panorama da mídia. Além disso, os ambientes estão além da influência direta dos atores, mas estimulam e exercem pressão sobre eles nos níveis de regime e nicho. As mudanças no ambiente podem levar décadas para ocorrer e está longe do alcance do controle de atores individuais, assim como de influências do regime em curto prazo (GEELS, 2005).

O regime sociotécnico representa as estruturas e práticas atuais caracterizadas por regras dominantes, instituições e tecnologias que se autorreforçam. O regime sociotécnico é dinamicamente estável porque há ligações mantidas e reproduzidas pelo alinhamento e 
coordenação de diferentes grupos de atores. Isso torna o regime resistente a transições tanto tecnológicas quanto sociais. Por ser de longo prazo, o processo de transição passa por fases, desde o seu pré-desenvolvimento, aceleração até chegar à fase de estabilização, que é a fase que os regimes se transformam, se modificam para formar novos regimes sociotécnicos. É evidente que organizar uma universidade tendo como fundamento único os instrumentos de avaliação não é suficiente para a inovação, a flexibilidade e a autonomia institucional. Por outro lado, é preciso que gestores acadêmicos e administrativos leiam com atenção os instrumentos, e a partir daí elaborem suas estratégias. Esse momento proporciona o primeiro passo para a inovação. O Instituto Nacional de Estudos e Pesquisas Educacionais Anísio Teixeira (INEP), por meio de suas avaliações, induz o sistema de ensino superior a realizar mudanças.

O nicho é definido como o "locus de inovações radicais" em que atores heterogêneos cumprem uma determinada função, são dedicados e alimentam o desenvolvimento de novidades tecnológicas. Incubado de influências de mercado e regulação, o nicho promove inovações que diferem fundamentalmente do regime vigente e geralmente exigem desenvolvimentos em nível de ambiente que abrem janelas de oportunidade no nível do regime. Portanto, a gestão da transição atribui transições sociotécnicas à interação de forças estabilizadoras no nível do regime com forças desestabilizadoras tanto do ambiente quanto dos níveis de nicho.

Os instrumentos de avaliação, ao mesmo tempo que valorizam as atividades realizadas e apropriadas, exigem das IES processos de avaliação constantes para verificar se o que foi planejado está adequado, bem como debates sobre a necessidade de revisão das estratégias e aprimoramento das diferentes atividades. Obviamente, as ações precisam ser efetivas e acompanhadas de políticas institucionais avaliadas pela comunidade acadêmica e pela sociedade. O que se espera é a incidência acadêmica e social nas atividades de ensino, pesquisa e extensão. As políticas existem para gerar mudanças e melhorias no aprendizado, na pesquisa e na extensão, além de benefícios na qualidade de vida das pessoas. Esse conjunto de atividades precisa ter vínculos com o entorno, especialmente com a cidade e a região em que a universidade está inserida.

A diversidade de processos elencados reflete a variedade de construções em relação aos contextos avaliados. A avaliação, assim também integrada, reforça o caráter formativo ao trabalhar com procedimentos que estimulam a participação dos autores do processo. Assim, um avanço está ocorrendo quando mudanças fundamentais estão ocorrendo em estruturas existentes por meio da interação de forças econômicas, sociais e culturais. 
A necessidade de transição sociotécnica no processo de avaliação institucional fica evidente e vale destacar que segundo Markard, Raven, Truffer (2012), essa mudança é uma transformação não necessariamente tecnológica. Todos esses apontamentos corroboram a necessidade de transição sociotécnica nas IES e essas mudanças podem vir por novos regulamentos, mas principalmente pela mudança de mentalidade das pessoas, todos aqueles atores envolvidos no nicho tecnológico.

\section{Considerações finais}

Esse artigo evidencia que o que predominou, ao longo dos diversos períodos e modelos avaliativos, foi o aspecto regulatório da avaliação institucional nas IES. Hoje, exige-se que as universidades sigam o SINAES nesse processo, no entanto, pouco se mudou nos procedimentos desde o PARU. O processo avaliativo não pode ser uma forma, um modelo que oferece um padrão único e técnico para analisar situações que são humanas, complexas, dinâmicas e inseridas em contextos diferenciados. É fato a necessidade de aperfeiçoamento contínuo, pois a avaliação tem recebido cada vez mais valor no contexto da busca por propostas e soluções.

A integração entre as dimensões avaliadas, considerando os diversos agentes e processos previamente relatados, além de contemplar os eixos do SINAES proporciona percepção global da vida institucional e torna notória a complexidade e riqueza do interrelacionamento da avaliação institucional. No sentido de contribuir para que a avaliação seja significativa para os indivíduos refletirem sobre seu papel institucional como agente promotor de mudanças, seus resultados devem ser amplamente divulgados e apropriados para ações futuras.

A inter-relação que se dá entre os diferentes processos organizados, para além de uma justaposição de resultados, permite ampliar, em diferentes graus, a compreensão da realidade. Ao mesmo tempo, buscou-se fortalecer e ampliar a avaliação institucional com maior participação e envolvimento, agregando todos os segmentos da comunidade acadêmica, egressos e empregadores, apropriando-se da rica heterogeneidade dos avaliadores. Avaliar, nesse sentido, não é um mero alinhamento de produtos e um simples somatório de serviços, mas a construção do saber, resguardados os princípios, as especificidades e as culturas de cada área (AFONSO, 2000).

Sob o mesmo viés, sugere-se a mudança de mentalidade dos atores envolvidos, contudo, levando em consideração a trajetória de nicho-acumulação. A transformação de nicho para o nível de regime não ocorre de uma só vez, mas gradualmente, portanto é uma acumulação de 
nichos. As mudanças em sua fase inicial se ligam aos padrões estabelecidos, muitas vezes para resolver gargalos específicos. É um processo gradual de reconfiguração. O que inicialmente pode aparecer como uma revolução acaba por ser o resultado de uma série de adaptações e mudanças ao longo do tempo.

A transição sociotécnica se aplica as cadeias produtivas à medida que tais cadeias precisam evoluir para ambientes mais sustentáveis e competitivos, seja por pressões governamentais ou mesmo por necessidade de nicho de mercado. Com base na pesquisa realizada, pode-se constatar o processo de avaliação ainda carece de desenvolvimento. A atividade ainda necessita de investimento em mudança dos padrões mentais e políticas públicas mais eficazes.

Entretanto, existem desafios para implantar novas sistemáticas. As mudanças, de modo geral, geram resistências e não é diferente no contexto estudado. No caso específico de avaliação institucional em IES, é necessário que haja uma mudança cultural, envolvendo todos os segmentos universitários para que a inovação em avaliação formativa seja consolidada como prática corrente.

A experiência de construção de instrumentos de avaliação institucional que aqui se relata demonstra a importância de se criar modelos que ofereçam respostas mais precisas e sustentadas acerca da diversidade de fatores implicados na vida universitária. Por fim, cabe destacar que este artigo não é conclusivo, mas sim uma ampliação da discussão do tema.

\section{Referências}

AFONSO, Almerindo Janela. Avaliação educacional: regulação e emancipação. São Paulo: Cortez, 2000.

ANDRIOLA, Wagner Bandeira; ARAÚJO Adriana Castro. Uso de indicadores para diagnóstico situacional de Instituições de ensino superior. Avaliação e Políticas Públicas em Educação, Rio de Janeiro, v. 26, n. 100, p. 645-663, 2018.

BALDIGEN, Francine Adriane. Maturidade e inovação na avaliação institucional nas instituições de ensino superior do setor público. 2018. Dissertação (Mestrado em Engenharia de Produção) - Universidade Federal do Rio Grande do Sul, Porto Alegre, 2018.

BARREYRO, Gladys Beatriz; ROTHEN, José Carlos. Para uma história da avaliação da educação superior brasileira: análise dos documentos do PARU, CNRES, GERES e PAIUB. Avaliação, Campinas; Sorocaba, v. 13, n. 1, p. 131-152, 2008. Disponível em: https://www.scielo.br/scielo.php?pid=S141440772008000100008\&script=sci_abstract\&tlng=pt. Acesso em: 22 out. 2019.

BAUREN, Ilse Maria; TEIXEIRA, Silvio Aparecido. Avaliação dos sistemas de controle gerencial em instituição de ensino superior com o performance management and control. 
Journal of Information Systems and Technology Management, Brasil, v. 11, n. 1, p. 169$192,2014$.

BESE, Regina Macedo Boaventura. Um Breve Histórico da avaliação institucional no Brasil. Revista Gestão Universitária, São Paulo, n. 100, p. 138-496, 2007. Disponível em: http://gestaouniversitaria.com.br/artigos/um-breve-historico-da-avaliacao-institucional-nobrasil. Acesso em: 22 out. 2019.

BITITCI, Umit et al. PM: challenges for tomorrow. International Journal of Management Review, United Kingdom, v. 14, n. 3, p. 305-327, 2012.

BRASIL. Lei no 10.861, de 14 de abril de 2004. Institui o Sistema Nacional de Avaliação da Educação Superior - SINAES e dá outras providências. Brasília, DF, 2004.

CASTRO, Rosângela Nunes Almeida et al. Integração de processos avaliativos em uma instituição de ensino superior brasileira. Avaliação, Campinas; Sorocaba, v. 23, n. 1, p. 5874, 2018. Disponível em: https://www.scielo.br/scielo.php?script=sci_arttext\&pid=S141440772018000100058. Acesso em: 22 out. 2019.

CORRÊA, Angela Cristina et al. Resistência à mudança na educação superior: design e operacionalização de um instrumento de medida para o MEES. Revista GUAL, Florianópolis, v. 6, n. 2, p. 55-78, 2013.

CRESWELL, John. Qualitative inquiry and research design: choosing among five approaches. 2. ed. Thousand Oaks: Sage, 2006.

CUNHA, Luiz Antônio. Nova reforma do ensino superior: a lógica reconstruída. Cadernos de Pesquisa, São Paulo, n. 101, p. 20-49, jul. 1997.

DIAS SOBRINHO, José. Avaliação: técnica e ética. Avaliação, Campinas, v. 6, n. 3, set. 2001. Disponível em: http://periodicos.uniso.br/ojs/index.php/avaliacao/article/view/1151. Acesso em: 22 out. 2019.

FALLEIROS, Ana Elisa de Souza; PIMENTA, Márcio Lopes; VALADÃO JUNIOR, Valdir Machado. O significado da autoavaliação institucional na perspectiva de técnicosadministrativos de uma universidade pública. Avaliação, v. 21, n. 2, p. 593-618, 2016. Disponível em: https://www.scielo.br/scielo.php?script=sci_abstract\&pid=S141440772016000200593\&lng=pt\&nrm=iso. Acesso em: 22 out. 2019.

FELIX, Glades Tereza; BERTOLIN, Julio Godoy; POLIDORI, Marlis Morosini. Avaliação da educação superior: um comparativo dos instrumentos de regulação entre Brasil e Portugal. Avaliação, Campinas; Sorocaba, v. 22, n. 1, p. 35-54, 2017. Disponível em: https://www.scielo.br/scielo.php?pid=S141440772017000100035\&script=sci_abstract\&tlng=pt. Acesso em: 22 out. 2019.

FRANCISCO, Thiago Henrique Almino et al. Análise epistemológica da avaliação institucional da educação superior brasileira: reflexões sobre a transposição de paradigmas. Avaliação, Campinas; Sorocaba, v. 20, n. 2, p. 531-562, 2015. Disponível em: https://www.scielo.br/scielo.php?pid=S141440772015000200531\&script=sci_abstract\&tlng=pt. Acesso em: 22 out. 2019. 
GEELS, Frank. Technological transitions as evolutionary reconfiguration processes: a multilevel perspective and a case-study. Research Policy, Amsterdam, v. 31, n. 8-9, p. 1257-1274, 2002.

GEELS, Frank. The dynamics of transitions in socio-technical systems: a multi-level analysis of the transition pathway from horse-drawn carriages to automobiles (1860-1930).

Technology Analysis \& Strategic Management, United Kingdom, v. 17, n. 4, p. 445-476 2005.

GEELS, Frank. The multi-level perspective on sustainability transitions: Responses to seven criticisms. Environmental Innovation and Societal Transitions, United Kingdom, n. 1, p. 24-40, 2011.

GIL, Antonio Carlos. Como elaborar projetos de pesquisa. 5. ed. São Paulo: Atlas, 2010.

HOFFMANN, Celina et al. O desempenho das universidades brasileiras na perspectiva do Índice Geral de Cursos (IGC). Educação e Pesquisa, Campinas, v. 40, n. 3, p. 651-666, 2014.

KEMP, René; ROTMANS, Jan. The management of the co-evolution of technical, environmental and social systems. In: WEBER, M.; HEMMELSKAMP, J. (eds). Towards environmental innovation systems. Berlin: Springer, 2010. p. 33-55.

LOORBACH, Derk Albert. Transition management: new mode of governance for sustainable development. Utrecht: International Books, 2007.

MARKARD, Jochen; RAVEN, Rob; TRUFFER, Bernhard. Sustainability transitions: an emerging field of research and its prospects. Research Policy, Amsterdam, v. 41, n. 6, p. 955967, 2012.

MARTINS, Gilberto de Andrade. Estudo de caso: uma estratégia de pesquisa. São Paulo: Atlas, 2006.

MILES, Lawrence Delos. Lawrence Delos Miles Value Foundation. 2019. Disponível em: https://web.archive.org/web/20110106035244/http://www.valuefoundation.org/biography.htm. Acesso em: 3 out. 2019.

MURMAN, Earll et al. Lean enterprise value: insights from MIT's Lean Aerospace Initiative. Suffolk: Aardvark editorial, 2002.

NEIVA, C. Avaliação institucional. Brasília: Dois Pontos, 1987.

PEDERNEIRAS, Marcleide Maria Macedo et al. Exame nacional de desempenho dos estudantes na visão de líderes formais. Avaliação e Políticas Públicas em Educação, Rio de Janeiro, v. 19, n. 71, p. 381-400, 2011.

PRODANOV, Cleber Cristiano. Metodologia do trabalho científico: métodos e técnicas da pesquisa e do trabalho acadêmico. 2. ed. Novo Hamburgo: Feevale, 2013.

PUCCIARELLI, Francesca; KAPLAN, Andreas. Competition and Strategy in Higher Education: Managing Complexity and Uncertainty. Business Horizons, Indiana, v. 59, n. 3, p. 311-320, 2016. 
RIBEIRO, Jorge Luiz Lordêlo de Sales. SINAES: o que aprendemos acerca do modelo adotado para avaliação do ensino superior no Brasil. Avaliação, Campinas; Sorocaba, v. 20, n. 1, p. 143-161, 2015. Disponível em:

https://www.scielo.br/scielo.php?script=sci_arttext\&pid=S1414-

40772015000100143\&lng=en\&nrm=iso\&tlng=pt. Acesso em: 22 out. 2019.

RISTOFF, Dilvo Ilvo. Universidade em foco: reflexões sobre a educação superior.

Florianópolis, SC: Insular, 1999.

SEMESP. Resultados dos processos de avaliação institucional podem ser melhorados.

2018. Disponível em: https://www.semesp.org.br/wp-content/uploads/2018/01/Resultados-

processos-avaliacao-institucional-melhorados-1.pdf. Acesso em: 04 out. 2019.

STEINHARDT, Isabel et al. Mapping the quality assurance of teaching and learning in higher education: the emergence of a specialty? Higher Education, Netherlands, v. 74, n. 2, p. 221237, 2016.

VAN RAAN, Anthony. Fatal attraction: conceptual and methodological problems in the ranking of universities by bibliometric methods. Scientometrics, Budapest, v. 62, n. 1, p. 133-43, 2005.

VENTURINI, Jonas Cardona et al. Percepção da avaliação: um retrato da gestão pública em uma instituição de ensino superior (IES). Revista de Administração Pública - RAP, Rio de Janeiro, v. 44, n. 1, p. 31-53, 2010.

VIEIRA, Rui; MAJOR, Maria João; ROBALO, R. Investigação qualitativa em contabilidade. In: MAJOR, M. J.; VIEIRA, R. (ed.). Contabilidade e controle de gestão: teoria, metodologia e prática. Lisboa: Escolar Editora, 2009. p. 301-331. 